\title{
Correction to: Exemplification in Undergraduate Biology: Dominant Images and Their Impact on Student Acquisition of Conceptual Knowledge
}

\author{
Alandeon W. Oliveira • Erin Johnston • \\ Adam Oliver Brown \\ Published online: 10 July 2018 \\ (C) Ontario Institute for Educational Studies (OISE) 2018
}

\section{Correction to: Can J Sci Math Techn \\ https://doi.org/10.1007/s42330-018-0017-0}

In the original version of the article, Alandeon W. Oliveira's first name was misspelled. It is correct as shown here. The original article has been updated.

The online version of the original article can be found at https://doi.org/10.1007/s42330-018-0017-0

A. W. Oliveira $(\bowtie)$

Educational Theory and Practice Department, State University of New York, 1400 Washington Ave., ED 113B, Albany, NY 12222, USA

e-mail: aoliveira@albany.edu

E. Johnston - A. O. Brown

Department of Biology, Faculty of Science, University of Ottawa, Ottawa, Ontario K1N 6N5, Canada

\section{A. O. Brown}

e-mail: abrown@uottawa.ca

\section{A. O. Brown}

Faculty of Education, University of Ottawa, Ottawa, Ontario K1N 6N5, Canada 